\title{
Taking a close look at death
}

\author{
Roy Porter
}

\section{Expectations of Life. A Study of the Demography, Statistics, and History of World} Mortality. By H. O. Lancaster. Springer-Verlag: 1990. Pp. 605. £114, \$159.

MEDICAL scientists and historians both have a stake in understanding the role of disease in the rise of civilization, but they often approach the problem with very different preconceptions. The medical mind anticipates encountering solid evidence (archival, skeletal) upon which to train its technical skills (clinical, epidemiological, palaeopathological and so forth), and is perhaps disposed to view the springs of progress rather biologistically. By contrast, the historian is probably in the first place less optimistic about our capacity even to identify the pestilences of the past, and in any case will be anxious to stress multifactoriality, the role of culture as well as nature. Politics, morals, and wealth distribution often have far greater impact than the transmigrations of microorganisms upon morbidity and mortality.

Each view has its point, and not least of the virtues of H. O. Lancaster's magisterial survey of world mortality lies in its sensitivity to both. As may be expected from an MD who is an emeritus professor of mathematical statistics, epidemiology constitutes the core of this project. Professor Lancaster devotes more than half his book to a meticulous discussion of the spectrum of disease types (bacterial, virus, arthropod-borne, neoplastic and so on) which have primarily determined death rates. But, for all his array of graphs and statistics, he never loses sight of the drastic deficiency of clinical information and mortality statistics for three-quarters of the globe until the past century. And he shows due caution regarding our capacity to establish fine retrospective diagnostic distinctions, especially amongst the numerous disenteric infections that decimated the great conurbations before the advent of compulsory public health and scientific therapeutics: after all, as he eruditely demonstrates, the stabilization of disease terminology is itself a product of modernity. (Exceptionally to his wise scepticism, Lancaster is confident that the 'great plague' of Athens can be put down to smallpox; most historians of ancient diseases would demur.)

After surveying the great diseases, Lancaster examines the other main causes of mortality (famine, war and so on) in the light of available demographic statistics, before posing the key question: how does the history of diseases influence social change, and thus shape the patterns of world population? Ever since Malthus, these variables have been fiercely disputed. Malthus pictured biology (disease, famine) checking the progress of society. Many modern demographers have stood Malthus on his head, arguing that society itself has been the cradle of disease (through malnutrition no less than insanitary environments). Nowadays, though 'agriscience' may have sprung the malthusian trap, it is surely creating new ones in its place, quite unknown to Malthus above all, global environmental degradation. How does Lancaster assess these variables?

He contends - surely correctly - that the history of the past 500 years reveals sharply divergent patterns for the developed and the undeveloped worlds. In the West, commercialization, industrialization and urbanization first exacerbated epidemic mortality, but subsequently provided the abundance and the technical know-how to eliminate epidemics, while artificially containing population growth. By contrast, the tale of the developing countries has been one of diminishing real mastery over the environment (sometimes masquerading as agricultural improvement'), and the breakdown of traditional demographical equilibria. The successes of tropical medicine have created fresh problems in their wake (witness AIDS in central Africa).

Lancaster is sometimes content to let his material speak for itself, and a more energetic evaluation of rival interpretations would have been welcome: for instance, the path-breaking revisionist reading by Ester Boserup of Population and Technological Change (University of Chicago Press, 1981) is surprisingly absent from his otherwise spectacular 100-page bibliography. This points to a certain tension in the conception of this book - is it intended mainly as a work of synthesis or of reference? Sometimes the itch to be exaustive gets the upper hand, as when a paragraph on bridge disasters is followed by a computation of mortality from lightning. Nevertheless, not least thanks to Lancaster's unfailing ability to convey highly technical matters in a lucid prose, this is a volume which is sure to be widely consulted by all concerned with the history of mortality.

Roy Porter is at the Wellcome Institute for the History of Medicine, 183 Euston Road, London NW1 2BP, UK.

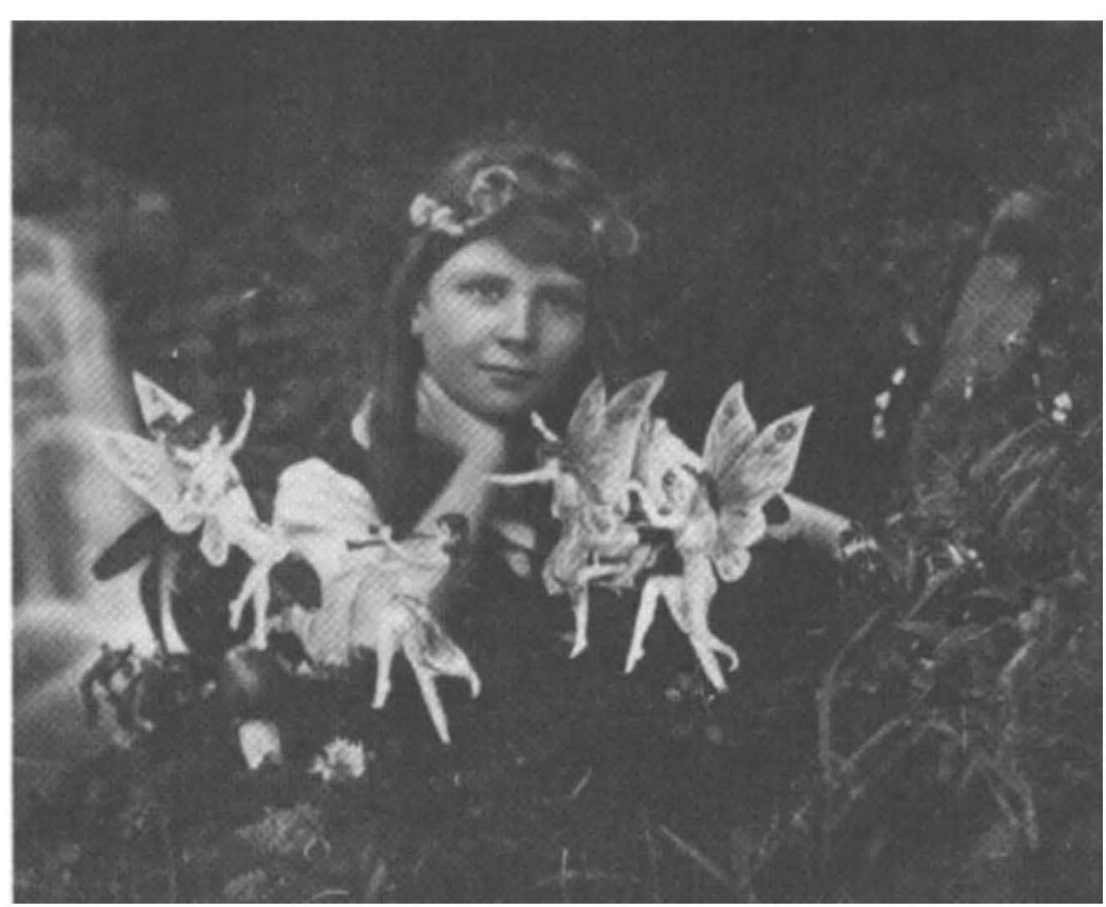

The first, and best known, of the Cottingley fairy photographs. In 1917 Elsie Wright (aged 15) and Frances Griffiths (aged 9) constructed the photographs using cardboard cutouts held in place with hat pins - in this photograph the girls forgot to attach wings to the fairy second from the left. The photographs continued to impress until 1983 when Wright and Griffiths revealed the manner of fabrication. Reproduced from Fake? The Art of Deception edited by $\mathrm{M}$. Jones, the photographs are part of a collection of fakes from all fields portrayed in the book; published to coincide with the exhibition at the British Museum ( 9 March until 2 September). The volume contains 'evidence' of a merman, furry trout and unicorn's horn but also includes chapters on scientific detection of fakes and the limits of expertise. Published by British Museum Publications, price hbk £25; pbk £16.95. Published by the University of California Press in the United States, \$49.95; \$24.95. 